\title{
Assessment of Acute Mountain Sickness: How to integrate the advantages of the Lake Louise Score and the Chinese AMS Score
}

\author{
Yu Wu \\ Army Medical University \\ Zhifeng Zhong \\ Army Medical University \\ Jiaxin Xie \\ Army Medical University \\ Simin Zhou \\ Army Medical University \\ Yuqi Gao \\ Army Medical University \\ Jian Chen \\ Army Medical University
}

Peng Li ( $\sim$ lipengtmmu@163.com )

Army Military Medical University https://orcid.org/0000-0002-3902-8102

Research

Keywords: acute mountain sickness; Lake Louise Score; Chinese AMS Score; diagnostic criteria; questionnaires

Posted Date: August 28th, 2020

DOI: https://doi.org/10.21203/rs.3.rs-63029/v1

License: (c) (7) This work is licensed under a Creative Commons Attribution 4.0 International License. Read Full License 


\section{Abstract}

Aims: To compare the differences in acute mountain sickness (AMS) incidence between two AMS diagnostic scoring criteria, including the Lake Louise Score and the Chinese AMS Score.

Methods: A total of 2486 young men completed questionnaires after flying from Chendu (500 m) to Lasha (3658 m). The AMS incidence was investigated using a questionnaire that contained the scoring criteria for the LLS and CAS. To determine the grouping of all the symptoms on the AMS questionnaire, a systematic cluster analysis and two-step cluster analysis were used to analyse various symptoms and cases separately.

Results: The AMS incidence was 37.5\% ( $\mathrm{n}=932)$ according to the LLS, in which the cut-off point depended on headache and a total score $\geq 3$, and $59.3 \%$ ( $\mathrm{n}=$ 1473) according to the CAS, in which the cut-off point depended on headache, vomiting or a total score $\geq 5$. The LLS and CAS outcomes had a significant positive correlation (Spearman's rho $=0.918, \mathrm{P}<0.05$ ) and were moderately consistent (kappa value $=0.488, \mathrm{P}<0.001$ ). The positive AMS incidence determined by the CAS was significantly higher than that by the LLS $(P<0.001)$. Compared with the LLS, the sensitivity was $100 \%$, the specificity was $65.23 \%$, the positive predictive value was $63.34 \%$, and the negative predictive value was $100 \%$ for the CAS in the diagnosis of AMS. The CAS identified all AMS subjects diagnosed by the LLS, and an additional 541 subjects. Of all the symptoms investigated, the dominant symptoms were fatigue ( $59.3 \%$ ), dizziness (55.0\%), headache $(50.6 \%)$, chest tightness (40.4\%), and shortness of breath (37.2\%), and the last two symptoms were not included in the LLS. The cluster analysis show that chest distress, shortness of breath and palpitations were relatively independent of the major symptoms assessed by the LLS.

Conclusion: The CAS had testing characteristics for diagnosing AMS similar to those of the Lake Louise Questionnaire Score, and the CAS diagnosed a higher prevalence of AMS than the LLS. It is suggested that chest distress and shortness of breath should be paid adequate attention and taken into account in AMS diagnostic criteria in the next revision to better diagnosis and study AMS.

\section{Background}

Acute mountain sickness (AMS) refers to a series of clinical syndrome that occur when people ascend to a plateau > $2500 \mathrm{~m}$ above sea level from a plain or from a plateau to a higher altitude over a short period of time[1]. These symptoms usually manifest as headache, dizziness, nausea, anorexia, fatigue, and sleep disturbances, and they often occur within a few hours $(6-12 \mathrm{~h})$ after reaching the plateau. Although AMS is often a self-limiting disease and these symptoms can resolve spontaneously after 3 to 7 days without treatment in most cases, AMS may progress to life-threatening high-altitude cerebral edema (HACE) [2] or high-altitude pulmonary edema (HAPE) in fewer than $1 \%$ of patients. AMS remains a common consequence of rapid ascent. Globally, the incidence of AMS differs greatly in different reports (varying from 10 to $80 \%$ )[3, 4]. The incidence is closely related to the ascent rate, altitude attained, season, individual predisposition, including physiology, psychology and genetic susceptibility, and specific behaviours and activities[5], including activity level at high altitude and medical prophylaxis, which influence the development of AMS [6, 7]. In addition, quantification of the prevalence and severity of AMS varies according to the diagnostic criteria used to establish a diagnosis of AMS.[8, 9].

At present, the diagnosis of AMS does not have reliable, clinical physiological indicators as diagnostic markers[10]. Its diagnosis relies only on individual selfassessment of the intensity of symptoms using a variety of diagnostic criteria [11]. With the development of high-altitude disease research, various altitude sickness scoring systems have been applied to the diagnosis of acute mountain diseases, such as the Hackett clinical score[12], the Environmental Symptoms Questionnaire (ESQ)[13], the AMS-Cerebral score (AMS-C), the clinical functional score (CFS), the visual analog scale (VAS)[4, 14], the Lake Louise Score (LLS) [15], and the Chinese AMS Score (CAS) [16]. These diagnostic scales can be divided into self-assessment questionnaires of symptoms and clinician assessment scales. The Hackett AMS score is a scoring system consisting of a structured interview that mainly investigates altitude-related headaches, nausea and five other symptoms. Physical examination emphasizes periorbital or peripheral oedema, respiratory rate, pulmonary rales and ataxia[12]. The ESQI-IV was introduced by the US military in the late 1970s and early 1980 s to obtain information on the incidence and severity of symptoms following exposure to different climatic conditions, including acute altitude exposure, and contained 52-67 items spanning a wider range of environmental reactions[13, 17-19]. The AMS-C and LLS were derived from the initial Environmental Symptoms Questionnaire score. The VAS is mainly used to identify the severity of symptoms and evaluate AMS; it is the most recent tool to be used for evaluating AMS [4, 14]. The LLS is currently an internationally recognized, useful research tool for diagnosing AMS[11]. The LLS assesses five symptoms (headache, dizziness, fatigue, gastrointestinal reactions, and difficulty sleeping) of AMS using a 4-point Likert scale[15]. Due to the simplicity and reliability of the LLS, it is widely used in clinical diagnosis and scientific research. However, it still has some shortcomings and needs constant improvement. An international consensus was presented that made some adjustments to the LLS, including eliminating disturbed sleep as a questionnaire item in 2018[20].

China has a large plateau area and the largest AMS patient population in the world. Some scholars and doctors often use the Chinese AMS Score (CAS) to diagnose AMS in China. The CAS was published in the Third Chinese National Symposium on High Altitude Medicine of the Chinese Medical Association in September 1995[16, 21]. In contrast to the LLS, which emphasizes the importance of headaches as a primary criterion for diagnosing AMS, the CAS stipulates that headache and vomiting are non-obligatory symptoms that may indicate AMS; the CAS indicates that patients with no headache can also be diagnosed with AMS when other symptoms are very serious[22]. The CAS includes a series of symptoms not mentioned in the LLS: dizziness, nausea, palpitation, shortness of breath, chest distress, blurred vision, insomnia, lethargy, anorexia, abdominal distension, diarrhoea, constipation, lip cyanosis, and numbness of the extremities (Table 1). In previous studies, some scholars compared the difference between the two AMS scoring systems [8, 9] found that the CAS outcomes were in good agreement with the LLS outcomes and provided a more positive diagnosis. However, how these two scoring systems perform relative to one another has not been studied in detail, and the sample sizes of the previous studies were small.

Therefore, we compared the relative performance of the Chinese AMS Score against what is commonly considered a reference standard, i.e., the Lake Louise Score, using 3 to indicate a positive test result. We analysed a group of 2486 subjects who flew from Chengdu (500 m) to Lhasa ( $3658 \mathrm{~m})$ and studied the 
relationship between the LLS and CAS diagnostic criteria for AMS to explore whether the limited symptoms of the LLS could cover the actual state of AMS well in a large sample population and whether the CAS including more symptoms is useful for improving the LLS.

\section{Methods}

\section{Subjects}

We enrolled 2503 participants at $500 \mathrm{~m}, 17$ of whom were excluded for incomplete data. Thus, we analysed data obtained from the remaining 2486 subjects. Participants were required to have abstained from tobacco and alcohol for the previous 6 months, and other disease factors were excluded. The participants were all healthy young men (average age $18.33 \pm 1.23$ years, range 16 to 24 years) and lived below $2500 \mathrm{~m}$ altitude; no subject had a medical or AMS history. In December 2012, the subjects were transported by plane for almost two and a half hours from Chengdu (500 m) to Lhasa in Tibet (3658 $\mathrm{m}$ ). Before entering the plateau, the subjects underwent high-altitude health education and unified preventive measures but did not take preventive drugs. After arriving on the plateau, the individuals with serious symptoms were treated with drugs after a doctor's diagnosis. This study was approved by the Ethics Committee of the Army Military Medical University.

\section{Questionnaires And Scoring Systems}

We designed a questionnaire that included all the detailed symptoms covered by the LLS and CAS. Headache, gastrointestinal symptoms, fatigue and/or weakness, dizziness/lightheadedness, and sleep disturbance were each assigned a grade of 0 to 3 points. The remaining symptoms, i.e., palpitations, shortness of breath, chest distress, dazzling/blurred vision, anorexia, abdominal distension, diarrhoea, constipation, cyanosis of the lips, and numbness of the extremities, were recorded as 0 or 1 point. The questionnaire also collected demographic information on the subjects: age, ethnicity, individual history of AMS, smoker or non-smoker status, and permanent residence.

At 9 o'clock in the morning on the second day after arrival on the plateau, a questionnaire was issued by 5 trained investigators. AMS symptom scores were evaluated according to the LLS and CAS.

\subsection{The Lake Louise Scoring system}

The LLS examines five symptoms: headache, gastrointestinal symptoms, fatigue/weakness, dizziness/light-headedness, and difficulty sleeping. Each symptom was divided into none (score of 0), mild (1), moderate (2), and severe (3) (Table 1). The presence of headache plus a cumulative score of 3 or greater is usually considered positive for AMS. Mild AMS was considered 3-5 points, and moderate or severe AMS was considered a score of 6 or greater (Table 2). Although the LLS was adjusted in 2018 to remove sleep disturbance as a questionnaire item[20], considering the consistency and coherence of the research, we still used the old version of the LLS here.

\subsection{The Chinese AMS Scoring system}

The standard CAS examines headache, vomiting, palpitation, short breath, vertigo, insomnia, drowsiness, decreased food appetite, abdominal distension, diarrhoea, constipation, lip cyanosis, hand and foot numbness and other symptoms. Headache and nausea/vomiting were divided into four grades, corresponding to 1, 2, 4, and 7 points, and other symptoms were recorded as 0 or 1 point each (Table 1). According to the total CAS outcome, AMS was divided into 4 degrees: essentially no reaction (total score $<5$ points), mild reaction [headache $(+)$ or vomiting $(+)$ or total score of 5 to 10 points], moderate reaction (headache $(++)$ or vomiting (++) or total score between 10 and 15 points] and severe reaction [headache (+++) or vomiting (+++) or total score $\geq 16$ ] (Table 2$)$. A mild reaction was considered to be positive for AMS[16, 21]. 
Table 1

Summary of the Lake Louise Score (LLS) and Chinese Acute Mountain Sickness Score (CAS)

\begin{tabular}{|c|c|c|c|c|}
\hline & LLS $^{\mathbf{a}}$ & & CAS $^{b}$ & \\
\hline Symptom & $\begin{array}{l}\text { Detailed } \\
\text { description }\end{array}$ & Score & Detailed description & Score \\
\hline Headache & No headache & 0 & No headache,no suffering expression $\llbracket$ no effect on daily activity. & 1 \\
\hline \multirow[t]{3}{*}{ Headache } & Mild headache & 1 & $\begin{array}{l}\text { Mild headache with suffering expression;obvious improvement of headache after } \\
\text { taking regular analgesic medicinelno effect on daily activity. }\end{array}$ & 2 \\
\hline & $\begin{array}{l}\text { Moderate } \\
\text { headache }\end{array}$ & 2 & $\begin{array}{l}\text { Moderate headache with suffering expression;slight improvement of headache } \\
\text { after taking regular analgesic medicine } d \text { daily activity is affected. }\end{array}$ & 4 \\
\hline & $\begin{array}{l}\text { Severeheadache, } \\
\text { incapacitating }\end{array}$ & 3 & $\begin{array}{l}\text { Severe and unbearable headache;in bed and unable to get up } \llbracket \text { no effect of regular } \\
\text { analgesic medication. }\end{array}$ & 7 \\
\hline \multirow{5}{*}{$\begin{array}{l}\text { Gastrointestinal } \\
\text { Gastrointestinal symptoms }\end{array}$} & None & 0 & None & 0 \\
\hline & $\begin{array}{l}\text { Poor appetite or } \\
\text { nausea }\end{array}$ & 1 & Vomiting 1 to 2 times/d,which does not interfere with daily activities. & 2 \\
\hline & $\begin{array}{l}\text { Moderate nausea } \\
\text { \&/or vomiting }\end{array}$ & 2 & Vomiting 3 to 4 times/d,which interferes with daily activities. & 4 \\
\hline & $\begin{array}{l}\text { Severe nausea } \\
\& / \text { or vomiting }\end{array}$ & 3 & $\begin{array}{l}\text { Vomiting more than } 3 \text { times/d;patients confined to bed and no relief after } \\
\text { medication. }\end{array}$ & 7 \\
\hline & & & Nausea,anorexia $\square$ abdominal distension $\llbracket$ diarrhea $\llbracket$ constipation & $\begin{array}{l}1 \\
\text { point } \\
\text { each }\end{array}$ \\
\hline \multirow{5}{*}{$\begin{array}{l}\text { Fatigue } \\
\text { Fatigue \&/or weakness }\end{array}$} & Not tired or weak & 0 & & \\
\hline & $\begin{array}{l}\text { Mild fatigue/ } \\
\text { weakness }\end{array}$ & 1 & & \\
\hline & $\begin{array}{l}\text { Moderate fatigue/ } \\
\text { weakness }\end{array}$ & 2 & & \\
\hline & $\begin{array}{l}\text { Fatigue \&/or } \\
\text { weakness }\end{array}$ & 3 & & \\
\hline & $\begin{array}{l}\text { Severe fatigue/ } \\
\text { weakness }\end{array}$ & & & \\
\hline \multirow{4}{*}{$\begin{array}{l}\text { Neurological } \\
\text { Dizziness/lightheadedness }\end{array}$} & Not dizzy & 0 & Dizziness/light-headedness & \multirow{4}{*}{$\begin{array}{l}1 \\
\text { point } \\
\text { each }\end{array}$} \\
\hline & Mild dizziness & 1 & Dazzling or blurred vision & \\
\hline & $\begin{array}{l}\text { Moderate } \\
\text { dizziness }\end{array}$ & 2 & Numbness of the extremities & \\
\hline & $\begin{array}{l}\text { Severe dizziness, } \\
\text { incapacitating }\end{array}$ & 3 & & \\
\hline \multirow{5}{*}{$\begin{array}{l}\text { Sleep } \\
\text { Difficulty sleeping }\end{array}$} & $\begin{array}{l}\text { Slept as well as } \\
\text { usual }\end{array}$ & 0 & \multirow{5}{*}{$\begin{array}{l}\text { Insomnia } \\
\text { Lethargy }\end{array}$} & \multirow{5}{*}{$\begin{array}{l}1 \\
\text { point } \\
\text { each }\end{array}$} \\
\hline & $\begin{array}{l}\text { Did not sleep as } \\
\text { well as usual }\end{array}$ & 1 & & \\
\hline & $\begin{array}{l}\text { Woke many times, } \\
\text { poor sleep }\end{array}$ & 2 & & \\
\hline & Difficulty sleeping & 3 & & \\
\hline & $\begin{array}{l}\text { Could not sleep at } \\
\text { all }\end{array}$ & & & \\
\hline $\begin{array}{l}\text { Respiratory/ circulatory } \\
\text { system }\end{array}$ & & & Palpitation,Shortness of breath $\square$ Chest distress $\square$ Cyanosis of the lips & \\
\hline
\end{tabular}

a. Score requires the presence of headache (the other criteria do not) and at least 1 other symptom to establish an AMS diagnosis. A score of 3 or more indicates AMS.

b. Presence of headache, vomiting, or a total score of 5 indicates AMS. 


\begin{tabular}{|lll|}
\hline & LLS & CAS \\
\hline Diagnostic criteria & Headache, at least one other symptom, total score $\geq 3$ & Headache or vomiting or total score $\geq 5$ \\
\hline Cut-off value & Total score $\geq 3$ & Total score $\geq 5$ \\
\hline Degree & & $1-4$ \\
\hline Absent $( \pm)$ & $0-2$ & Headache + , or vomiting + ; or total score of $5-10$ \\
\hline Mild $(+)$ & $3-5$ & Headache,++ or vomiting ++ ; or total score of $11-15$ \\
\hline Moderate $(++)$ & 6 or more & Headache,+++ or vomiting $+++;$ or total score of $\geq 16$ \\
\hline Severe $(+++)$ & & Het
\end{tabular}

\section{Statistical Analysis}

Statistical analysis was performed using PASW Statistics 20 software (IBM Corp., Armonk, NY). The numeration data are expressed in terms of the frequency, and the Spearman correlation analysis, the Kappa consistency test and paired $\chi 2$ test (McNemar's test) were used for comparisons of the two scoring criteria. The Bonferroni-corrected chi-square method was used for comparisons between groups. Cluster analysis of symptoms was based on systematic cluster analysis. The cluster method was an inter-group link, and the measurement standard was Pearson correlation with 1 correlation coefficient as the distance between symptoms. Case clustering was performed with two-step clustering, and the log-likelihood was used to measure the distance. The clustering judgement was based on the Bayesian information criterion (BIC). All tests were two-tailed, and a $P$-value $<0.05$ was considered significant.

\section{Results}

\section{The incidence of AMS determined by the two scoring systems}

In all 2486 subjects, the incidence of AMS was 37.5\% $(n=932)$ using the LLS and 59.3\% using the CAS $(n=1473)$. There was a significant positive correlation between the LLS and CAS outcomes (Spearman's rho $=0.918, \mathrm{P}<0.05)$ (Fig. 1). The diagnostic results of the CAS and LLS were generally consistent, and the kappa value in the chi-square test was $0.488(\mathrm{P}<0.001)$. The results of McNemar's test showed that there was a difference in the diagnosis between the two scoring standards. The positive rate of CAS-determined AMS was significantly higher than that of LLS-determined AMS $(X=565.61, P=0.000)$.

Both the CAS and LLS were evaluated by symptomatology scoring in a similar way. However, due to the different symptoms and weights assigned (Table 1 , Table 2), the incidence determined by the CAS assessment was higher than that by the LLS (59.3\% vs $37.5 \%)$. The CAS had diagnostic accuracy for moderate and severe AMS similar to that of the LLS (16.9\% vs 17.2\%). However, the difference was significant for mild AMS (42.3\% vs 20.3\%) (Fig. 2).

\section{Diagnostic Accuracy Of The Cas}

As the current mainstream standard for AMS diagnosis, validated by LLS diagnoses of AMS, the AUC was $0.820(0.804-0.837 ; \mathrm{P}<0.01)$,indicating that the CAS was an accurately verified means of determining AMS diagnoses. The Youden index was 0.652 . Taking the LLS as a reference, the sensitivity, specificity, positive predictive value and negative predictive value of the CAS for the diagnosis of AMS were $100 \%, 65.18 \%, 63.20 \%$, and $100 \%$, respectively.

\section{Dominant symptoms}

We found that the five dominant symptoms in all subjects were fatigue (59.3\%), dizziness (55.0\%), headache (50.6\%), chest tightness (40.4\%), and shortness of breath (37.2\%) (Fig. 3, Table 3). Among them, chest tightness and shortness of breath were from the CAS scoring system and were not mentioned in the LLS system.

Ratio: The frequency of the symptoms/total number 
Table 3

Most frequent symptoms of AMS $(\mathrm{N}=2486)$

\begin{tabular}{|c|c|c|c|c|}
\hline & Absent (0) & Mild (1) & Moderate (2) & Severe (3) \\
\hline Fatigue & $1012(40.7 \%)$ & $1106(44.5 \%)$ & $325(13.1)$ & $43(1.7 \%)$ \\
\hline Dizziness & $1118(45 \%)$ & $1107(44.5 \%)$ & $238(9.6 \%)$ & $23(0.9 \%)$ \\
\hline Headache & $1227(49.4 \%)$ & $918(36.9 \%)$ & $289(11.6 \%)$ & $52(2.1 \%)$ \\
\hline Chest tightness* & $1481(59.6 \%)$ & $1005(40.4 \%)$ & & \\
\hline Shortness of breath* & $1562(62.8 \%)$ & $924(37.2 \%)$ & & \\
\hline \multirow[t]{2}{*}{ LLS Score } & Absent (0-2) & Mild (3-5) & Severe $(\geq 6)$ & \\
\hline & $1554(62.5 \%)$ & $505(20.3 \%)$ & $427(17.2 \%)$ & \\
\hline \multirow[t]{2}{*}{ CAS Score } & Absent $(1-4)$ & Mild (5-10) & Moderate $(11-15)$ & Severe $(\geq 16)$ \\
\hline & $1013(40.7 \%)$ & $1051(42.3 \%)$ & $349(14.0 \%)$ & $73(2.9 \%)$ \\
\hline
\end{tabular}

All the symptoms on the AMS questionnaire were analysed by correlation based on whether they appeared at the same time and were clustered by systematic cluster analysis. The results showed that the distance between 6 symptoms, such as blurred vision and 5 variables from the LLS, was far. Because of its low frequency in the population, it could not be considered a main symptom of AMS. The distance between 3 symptoms, such as palpitation, chest distress and shortness of breath, was small, and the symptoms were relatively independent. Taking a height of 0.72 as the point of penetration, the symptoms can be divided into two modules: (1) headache, dizziness, fatigue, difficulty sleeping, vomiting and anorexia, which are basically consistent with the 5 categories of the LLS, and (2) shortness of breath, palpitations, and chest tightness. The incidence of these symptoms was high in the population, and they are relatively independent of the classic LLS symptoms. The LLS scoring system cannot express the occurrence of these symptoms, so they should be regarded as important symptoms of AMS and were combined into 1 category at height $=0.86$. (Fig. 4).

AMS symptoms cluster analysis based on systematic cluster analysis. The cluster method was an inter-group link, and the measurement standard was Pearson correlation with 1-correlation coefficient as the distance between symptoms.

\section{Main Symptoms Of Lls Negative And Cas Positive}

We found that all subjects diagnosed with AMS by the LLS $(n=932)$ were also positive for AMS according to the CAS. However, a total of 541 subjects were judged AMS positive by the CAS and AMS negative by the LLS. Among them, the CAS identified 523 as mild, 14 as moderate and 4 as severe. No severe mountain sickness, such as acute pulmonary oedema or acute brain oedema, occurred. The symptoms with the highest incidence were headache in 327 (60.6\%), dizziness in 280 (51.9\%), chest distress in 256 (47.3\%), fatigue in 252 (46.6\%), shortness of breath in 243 (44.9\%), cyclosis of the lips in 189 (34.8\%) and palpitations in 169 (31.1\%) (Fig. 5). Chest distress, shortness of breath and so on led to the higher total CAS score of this part of the population, which met the CAS diagnostic criteria for AMS, but these symptoms were not included in the LLS, which led to the totally different results of 541 people using the two scoring systems.

The 541 cases were clustered using two-step clustering. After pre-clustering, six symptoms were considered less important variables (abdominal distention, diarrhoea, constipation, cyanosis of the lips, blurred vision, numbness of the extremities) and were deleted, and the remaining nine symptoms were used for two-step clustering again to obtain two clusters. Category 1 included 214 people (39.6\%) without headache but with fatigue, dizziness, palpitations, chest distress, shortness of breath, and 327 people (60.4\%) with headache and no other symptoms were included in Category 2 . The distribution of clustering symptoms is shown in Fig. 3a, and the comparison of clustering symptoms is shown in Fig. 3b.

In addition, we found that there were no headaches (with a score of 0 ) in the four subjects who were identified as having severe AMS but that there were very serious gastroenteric symptoms, with a score of 3 . At the same time, 3 people had fatigue/weakness, and 3 people had difficulty sleeping. According to the CAS standards, there were also some people with shortness of breath, chest distress, dazzling/blurred vision, cyanosis of the lips, numbness of the extremities and other symptoms. Their total LLS score was greater than 5. 
Table 4

Symptom distribution and scores of 4 subjects with severe AMS according to the CAS in 541.

\begin{tabular}{|c|c|c|c|c|c|c|c|c|c|c|}
\hline & Headache & $\begin{array}{l}\text { Gastrointestinal } \\
\text { symptoms }\end{array}$ & $\begin{array}{l}\text { Fatigue/ } \\
\text { weakness }\end{array}$ & $\begin{array}{l}\text { Dizziness/ } \\
\text { lightheadedness }\end{array}$ & $\begin{array}{l}\text { Difficulty } \\
\text { sleeping }\end{array}$ & $\begin{array}{l}\text { Shortness } \\
\text { of breath }\end{array}$ & $\begin{array}{l}\text { Chest } \\
\text { distress }\end{array}$ & $\begin{array}{l}\text { Dazzling/blurred } \\
\text { vision }\end{array}$ & $\begin{array}{l}\text { Cyanosis } \\
\text { of the } \\
\text { lips }\end{array}$ & $\begin{array}{l}\text { Numbness } \\
\text { of the } \\
\text { extremities }\end{array}$ \\
\hline $\begin{array}{l}\text { Case } \\
1\end{array}$ & 0 & 3 & 3 & 1 & 0 & 1 & 0 & 1 & 0 & 0 \\
\hline $\begin{array}{l}\text { Case } \\
2\end{array}$ & 0 & 3 & 2 & 2 & 1 & 1 & 0 & 1 & 0 & 1 \\
\hline $\begin{array}{l}\text { Case } \\
3\end{array}$ & 0 & 3 & 1 & 1 & 1 & 1 & 1 & 0 & 1 & 0 \\
\hline $\begin{array}{l}\text { Case } \\
4\end{array}$ & 0 & 3 & 2 & 0 & 1 & 0 & 1 & 1 & 1 & 1 \\
\hline
\end{tabular}

\section{Discussion}

This study compared the outcomes of two scoring criteria (the Lake Louise Score (LLS; score of $\geq 3$ ) and the Chinese AMS Score (CAS; score of $\geq 5$ )) on the assessment of AMS in a large group including a total of 2486 subjects who rapidly entered a high-altitude area (3658 $\mathrm{m}$ ) by plane. To the best of our knowledge, this is the first large-sample study on the incidence of AMS as determined by the LLS and CAS diagnostic criteria. The CAS had testing characteristics for diagnosing AMS similar to those of the LLS and showed a generally consistent trend with the LLS, and the CAS diagnosed a higher prevalence of AMS than the LLS criteria did.

The results of this study show that the incidence of AMS diagnosed by the LLS and CAS was $37.5 \%$ and $59.3 \%$, respectively. In studies that used an airplane approach, Harrison et al.[23] reported an AMS incidence of 33.3\% using the LLS criteria, and Ren et al.[24] reported an AMS incidence of 57.2\% using the standard CAS; our results are consistent with both of theirs. Because AMS evaluation lacks reliable biomarkers and clinical indicators, it mainly depends on the determination of some neurological, gastrointestinal and respiratory symptoms at high altitude. Both the CAS and LLS were evaluated by symptomatology scoring in a similar way. However, due to the different symptoms and weights assigned, the incidence determined by the CAS assessment was higher than that by the LLS (59.3\% vs 37.5\%). This was consistent with previous studies[8, 9]. The CAS had diagnostic accuracy for moderate and severe AMS similar to those of the LLS (16.9\% vs $17.2 \%)$. However, the difference was significant for mild AMS (42.3\% vs $20.3 \%)$.

To help improve the AMS diagnostic criteria, some scholars compared and evaluated the different scoring criteria. [25] [26] [27] [11] Some Chinese scholars have studied the difference between the LLS and CAS in defining AMS. Chen et al.[9] surveyed 339 males residing at sea level who travelled by train and car to $3200 \mathrm{~m}$. Wu et al.[8] surveyed 58 males who went by train and recorded the AMS incidence when they reached different altitude sites, ending at $3658 \mathrm{~m}$. They found that CAS outcomes were in good agreement with LLS outcomes and can accurately diagnose AMS, suggesting that combining the LLS and the CAS in applications of clinical diagnosis can more objectively diagnose AMS than one scoring system alone.

The LLS and CAS are self-report questionnaires that diagnose AMS using a subject's self-assessment of symptom intensity. The two scoring criteria have different scoring rules, resulting in different diagnostic results[20]. The LLS highlights the importance of headache as the main criterion for the diagnosis of AMS and demands the presence of headache, and a total score of 3 or more can diagnose AMS. It is generally believed that acute mountain sickness is associated with high-altitude cerebral oedema and that this pathophysiological process should be explored. It is believed that the vasodilation caused by hypoxia or its effectors may cause headache by activating the trigeminovascular system[28]. An alternative hypothesis is that early AMS is caused by mild high-altitude cerebral oedema[29]. AMS is the pathogenetic precursor to high-altitude cerebral oedema.

However, there are ongoing controversies about whether headache is a necessary criterion for the diagnosis of AMS[22, 30]. The CAS criteria mainly emphasize headache and vomiting, which are major but nonspecific symptoms in the diagnosis of AMS, and the weight of headache is still very high. According to the severity, whether a symptom affects activity ability and general drug treatment response, weight scores of $1,2,4$, and 7 are given. Even if subjects do not have headache or vomiting but merely have a total score of 5 or more, they could also be diagnosed with AMS. In this study, 541 subjects were diagnosed with AMS by the CAS, while they were diagnosed as AMS negative by the LLS. Although they had mild AMS as determined by the CAS and may not have progressed to life-threatening pulmonary and cerebral oedema, these people were still troubled by many typical symptoms (such as headache, vomiting, chest tightness, shortness of breath, etc.). Because there was no headache $(214,39.6 \%)$ or only headache and the total score of less than 3 ( $327,60.4 \%)$, AMS could not be diagnosed by the LLS. For example, four subjects with severe gastrointestinal symptoms were diagnosed with severe AMS by the CAS but were considered to not have AMS by the LLS due to no headache. This observation is in line with a new view of AMS: AMS might not be a single syndrome but may manifest in different ways and present as symptom clusters that vary between patients, such as headache, headache and sleep disorders, fatigue and respiratory symptoms, and gastrointestinal symptom clusters $[5,31]$. Therefore, whether headache should be a necessary item in the diagnosis of AMS and the difference in pathophysiological mechanisms between atypical manifestations without headache and typical AMS need further research and discussion. If we want to improve the AMS diagnostic criteria to achieve the desired diagnostic ability, we should consider a small number of people who have no headache but have more overall discomfort. It is beneficial for medical interventions to define them as AMS patients.

The LLS includes five independently assessed symptoms, while the CAS includes more than ten other types of symptoms, such as palpitation, chest tightness and shortness of breath, which are scored as 0 or 1 point. It is simpler to use the LLS to make diagnoses on the plateau, as it is conducive to rapidly diagnose patients. The CAS diagnostic criteria are more extensive but also increase the complexity of diagnosis. For example, the CAS takes into account the judgement-biasing effect of conventional drugs, while the LLS depends only on the subjective feelings of the participants. The additional symptoms included 
in the CAS can help medical staff to find more unadaptable people in time and to initiate appropriate treatment to alleviate the further development of symptoms.

The influence of high altitude on organisms involves nearly every organ system. However, the LLS did not include the symptoms of the effects of hypoxia on the respiratory system because scholars considered the primary significance of AMS to be its potential for progression to HACE.[32] However, high-altitude pulmonary edema (HAPE) is also a high-altitude illness with an incidence rate of approximately $0.1 \%$. HAPE that is ignored or unrecognized may pass rapidly through a stage of dyspnoea and progress overnight to severe encephalopathy and coma[32]. According to the survey results, the incidence of chest distress was $40.4 \%$, ranking fourth among symptoms, and the incidence of shortness of breath was $37.2 \%$, ranking fifth among symptoms, both of which are symptoms of the influence of a hypoxic environment on the respiratory system. The cluster analysis results also confirmed this point; shortness of breath and chest distress were relatively independent of the five symptoms on the LLS. Therefore, it is suggested that the two symptoms involved in the CAS should be included in the scoring system in future revisions of the standard. This helps AMS diagnostic instruments identify more potential patients and provide timely medical services to improve the living comfort and mobility of patients. The AMS diagnostic criteria have been continuously improving[20]. To better diagnosis and study AMS, we hope that our research can provide some help for the improvement of AMS scoring criteria.

Although this study had a large sample size, the participants were all young men, preventing generalizations from our sample to women and other age groups. The monitoring index was simple, as it only analysed and compared the main indexes and scores for AMS, but physiological indexes, such as pulse, blood pressure or blood oxygen saturation, were not recorded.

\section{Conclusion}

The CAS is a widely used diagnostic standard for AMS in China. Headache is considered a major but nonspecific symptom in the diagnosis of AMS, and the CAS also contains 15 other symptoms. In our study, the CAS had testing characteristics for diagnosing AMS similar to those of the LLS and showed a generally consistent trend with the LLS. The CAS diagnosed a higher prevalence of AMS than the LLS at $3658 \mathrm{~m}$ when travelled to by aircraft. Chest distress and shortness of breath are high frequency symptoms of AMS. It is suggested that they should be included in the scoring system in the next revision to better diagnosis and study AMS.

\section{Abbreviations}

AMS: Acute mountain sickness; LLS: Lake Louise Score; CAS: Chinese AMS Score; HACE: High-altitude cerebral edema; HAPE: High-altitude pulmonary edema; ESQ : Environmental Symptoms Questionnaire ; AMS-C: AMS-Cerebral score; CFS: Clinical functional score; VAS: Visual analog scale; BIC: Bayesian information criterion. BIC :Bayesian information criterion;

\section{Declarations}

\section{Ethics approval and consent to participate}

This study was approved by the Ethics Committee of the Third Military Medical University. We attached the informed consent to the questionnaire, and all participants written the informed consent before filling in the questionnaire. Ethical issues have been fully considered in the research process to protect the rights of participants.

\section{Consent for publication}

Not Applicable.

\section{Availability of data and materials}

The datasets are available from the corresponding author on reasonable request.

\section{Competing Interest}

The authors declare that they have no competing interests.

\section{Funding}

This research was supported by the National Natural Science Foundation of China (41977403), the Health Industry Scientific Research Special Project (201002012), and the National Science and Technology Support Program (2009BA185B01). The above projects provide funds for research and public publication.

\section{Authors' contributions}

YG and JC participated in the design of this study. YW and JC performed the experiment. YW ,ZZ and PL performed the data processing and statistical analysis. YW drafted the manuscript and PL, JX, SZ revised the manuscript. All authors read and agreed to its content and approved the final manuscript.

\section{Acknowledgements}


We would like to express sincere gratitude to Xinshu Chen, M.D., Yongjun Luo, M.D. Department of Military Medical Geography, Army Medical Training Base, Army Military Medical University ,for advice on the manuscript. We would like to thank the health department of the plateau military unit for providing the organization and assistance of the participants in this study.

\section{References}

1. Yuqi G: High Altitude Military Medicine: Chongqing Publishing House; 2005.

2. Hackett PH, Roach RC: High-Altitude Illness. New England Journal of Medicine 2001, 345(2):107-114.

3. Vardy J, Vardy J, Judge K: Acute mountain sickness and ascent rates in trekkers above $2500 \mathrm{~m}$ in the Nepali Himalaya. Aviation Space \& Environmental Medicine 2006, 77(7):742-744.

4. Van Roo JD, Lazio MP, Pesce C, Malik S, Courtney DM: Visual analog scale (VAS) for assessment of acute mountain sickness (AMS) on Aconcagua. Wilderness \& Environmental Medicine 2011, 22(1):7-14.

5. Meier D, Collet T-H, Locatelli I, Cornuz J, Kayser B, Simel DL, Sartori C: Does This Patient Have Acute Mountain Sickness? Jama 2017, 318(18):1810.

6. Peng QQ, Basang Z, Cui CY, Li L, Qian J, Gesang Q, Yang L, La Z, De Y, Dawa P et al: Physiological responses and evaluation of effects of BMI, smoking and drinking in high altitude acclimatization: a cohort study in Chinese Han young males. PLoS One 2013, 8(11):e79346.

7. Schneider M, Bernasch D, Weymann J, Holle R, Bartsch P: Acute mountain sickness: influence of susceptibility, preexposure, and ascent rate. Medicine \& Science in Sports \& Exercise 2002, 34(12):1886.

8. Wu J, Gu H, Luo Y: Differences Between the "Chinese AMS Score" and the Lake Louise Score in the Diagnosis of Acute Mountain Sickness. Medicine 2016, 95(21):e3512.

9. Chen GZ, Qin J, Yu J, Gao XB, Dong JQ, Lu W, Bian SZ, Zeng Y, Huang L: Incidence of acute mountain sickness in young adults at 3200 meters: comparison of the Lake Louise Scoring and Chinese Scoring Systems. Genetics and molecular research : GMR 2013, $12(4): 6790-6801$.

10. Hext F, Stubbings A, Bird B, Patey S, Wright A: Visual analogue scores in assessment of acute mountain sickness. High Altitude Medicine \& Biology 2011, 12(4):329.

11. Kayser B, Aliverti A, Pellegrino R, Dellaca R, Quaranta M, Pompilio P, Miserocchi G, Cogo A: Comparison of a visual analogue scale and Lake Louise symptom scores for acute mountain sickness. High Altitude Medicine \& Biology 2009, 11(1):69-72.

12. Hackett P: The Incidence, Importance, and Prophylaxis of Acute Mountain Sickness. The Lancet 1976, 308(7996):1149-1155.

13. Kobrick JL, Sampson JB: New inventory for the assessment of symptom occurrence and severity at high altitude. Aviation Space \& Environmental Medicine 1979, 50(9):925-929.

14. Wu J, Chen Y, Luo Y: Evaluation of the visual analog score (VAS) to assess acute mountain sickness (AMS) in a hypobaric chamber. Plos One 2014, 9(11):e113376.

15. Roach RC, Bartsch P, Hackett PH, et al. The Lake Louise acute mountain-sickness scoring system//Sutton JR, Houston CS, Coates. Hypoxia and Mountain Medicine. Vt, Burlington: Queen City Press,1993:272-274.

16. West JB: English translation of "Nomenclature, classification, and diagnostic criteria of high altitude disease in China". High Altitude Medicine \& Biology 2010, 11(2):169-172.

17. Kobrick JL, Johnson RF: Measurement of subjective reactions to extreme environments: The Environmental Symptoms Questionnaire. Military Psychology 1994, 6(4):215-233.

18. Beidleman BA, Fulco SRMS, Rock PB, Cymerman A: Validation of a Shortened Electronic Version of the Environmental Symptoms Questionnaire. High Altitude Medicine \& Biology 2007, 8(3):192-199.

19. Sampson JB, Kobrick JL: The environmental symptoms questionnaire: revisions and new filed data. Aviation Space \& Environmental Medicine 1980, 51(9 Pt 1):872.

20. Roach RC, Hackett PH, Oelz O, Bartsch P, Luks AM, Maclnnis MJ, Baillie JK, Lake Louise AMSSCC: The 2018 Lake Louise Acute Mountain Sickness Score. High Alt Med Biol 2018, 19(1):4-6.

21. Yin Z, Xie Y, Niu W, Wu Y, Cui S, Lu Y: Principles of Diagnosis and Treatment of benign form of Acute Mountain Sickness. Journal of Preventive Medicine of Chinese PLA 1997, 15(6):3.

22. West JB: Con: Headache should not be a required symptom for the diagnosis of acute mountain sickness. High Altitude Medicine \& Biology 2011, 12(1):23-25; discussion 27

23. Harrison MF, Anderson PJ, Miller AD, O'Malley KA, Richert ML, Johnson JB, Johnson BD: Physiological variables associated with the development of acute mountain sickness at the South Pole. Bmj Open 2013, 3(7):74-76.

24. Ren Y, Fu Z, Shen W, Jiang P, He Y, Peng S, Wu Z, Cui B: Incidence of high altitude illnesses among unacclimatized persons who acutely ascended to Tibet. High Altitude Medicine \& Biology 2010, 11(1):39.

25. Roeggla G, Roeggla M, Podolsky A, Wagner A, Laggner AN: How can acute mountain sickness be quantified at moderate altitude? Journal of the Royal Society of Medicine 1996, 89(3):141-143.

26. Maggiorini M, Müller A, Hofstetter D, Bärtsch P, Oelz O: Assessment of acute mountain sickness by different score protocols in the Swiss Alps. Aviation Space \& Environmental Medicine 1998, 69(12):1186.

27. Dellasanta P, Gaillard S, Loutan L, Kayser B: Comparing questionnaires for the assessment of acute mountain sickness. High Altitude Medicine \& Biology 2007, 8(3):184-191. 
28. Basnyat B , Murdoch D R . High-altitude illness.[J]. Lancet, 2003, 361(9373):1967-1974.

29. Luks AM, Swenson, Erik R, B?rtsch, Peter.: Acute high-altitude sickness. European Respiratory Review An Official Journal of the European Respiratory Society 2017, 26(143):160096.

30. Roach R, Kayser B, Hackett P: Pro: Headache should be a required symptom for the diagnosis of acute mountain sickness. High Altitude Medicine \& Biology 2011, 12(1):21.

31. Hall DP, Maccormick IJC, Phythian-Adams AT, Rzechorzek NM, Hope-Jones D, Cosens S, Jackson S, Bates MGD, Collier DJ, Hume DA: Network Analysis Reveals Distinct Clinical Syndromes Underlying Acute Mountain Sickness. Plos One 2014, 9.

32. Gallagher SA, Hackett PH: High-altitude illness. Emerg Med Clin North Am 2004, 22(2):329-355, viii.

\section{Figures}

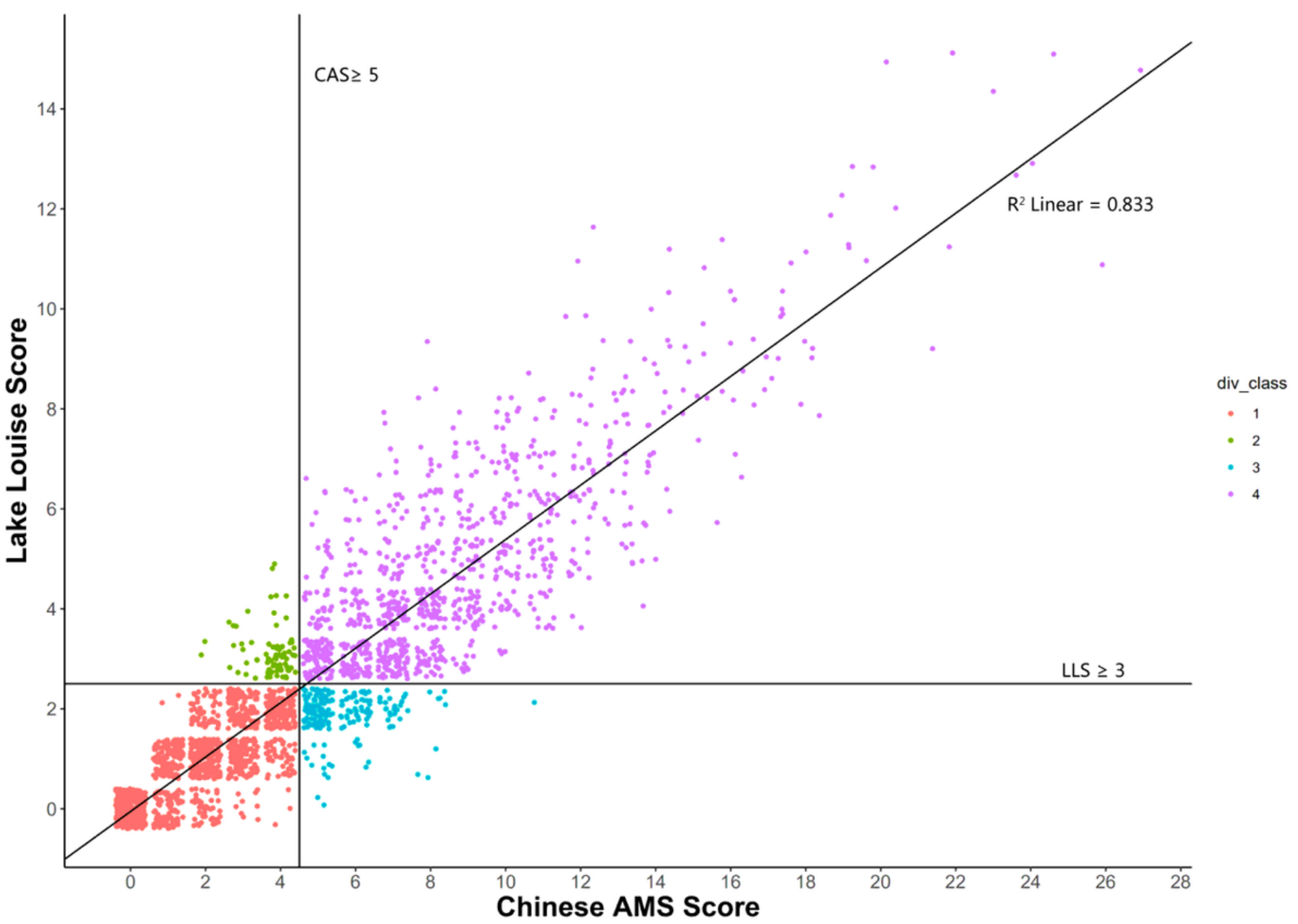

Figure 1

Correlation between the Lake Louise Score (LLS) and the Chinese AMS Score (CAS) at $3680 \mathrm{~m}$. The black solid line is the overall fit line, and the solid points represent the CAS and LLS scores of each subject, with R2 linear $=0.833$ and Spearman's rho $=0.918, P<0.05$. 

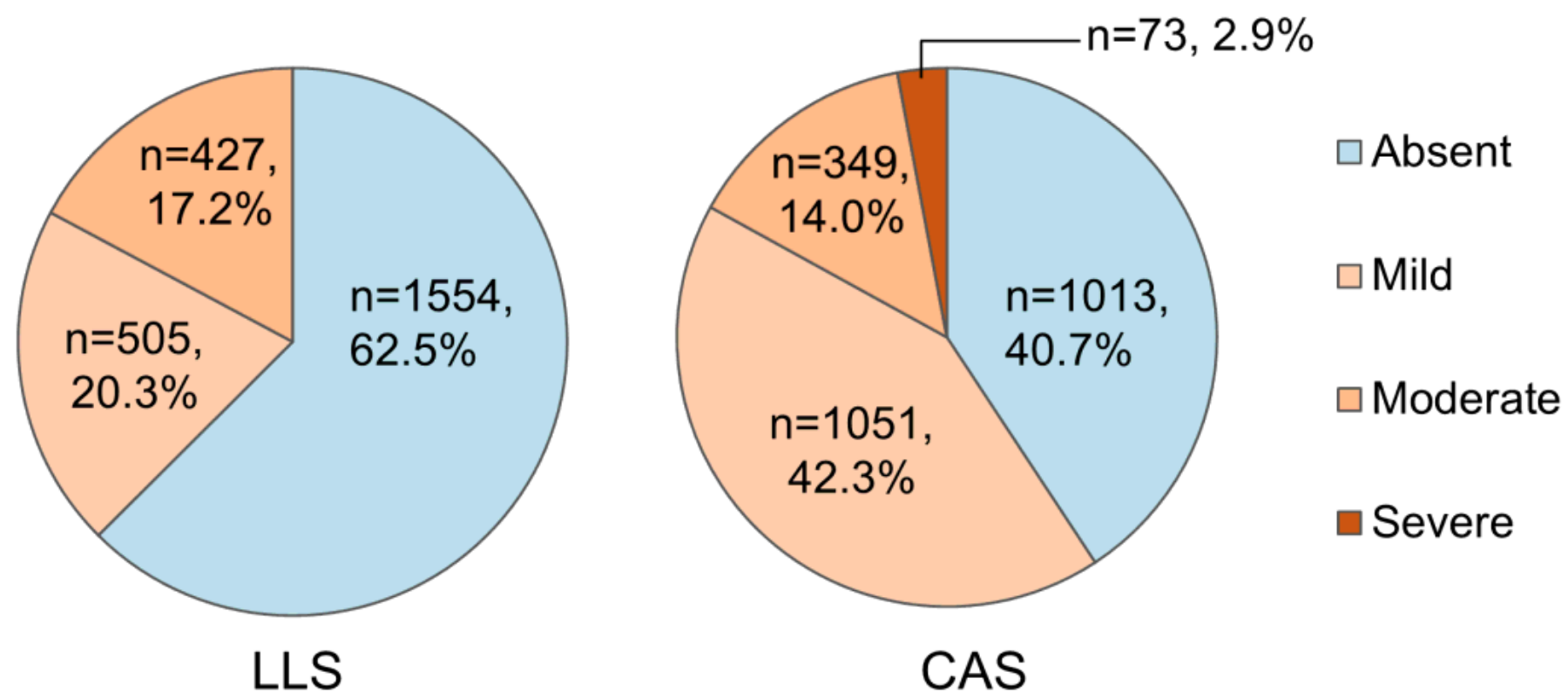

Figure 2

Results for the degree of acute mountain sickness according to the Lake Louise Score (LLS) and the Chinese AMS Score (CAS)

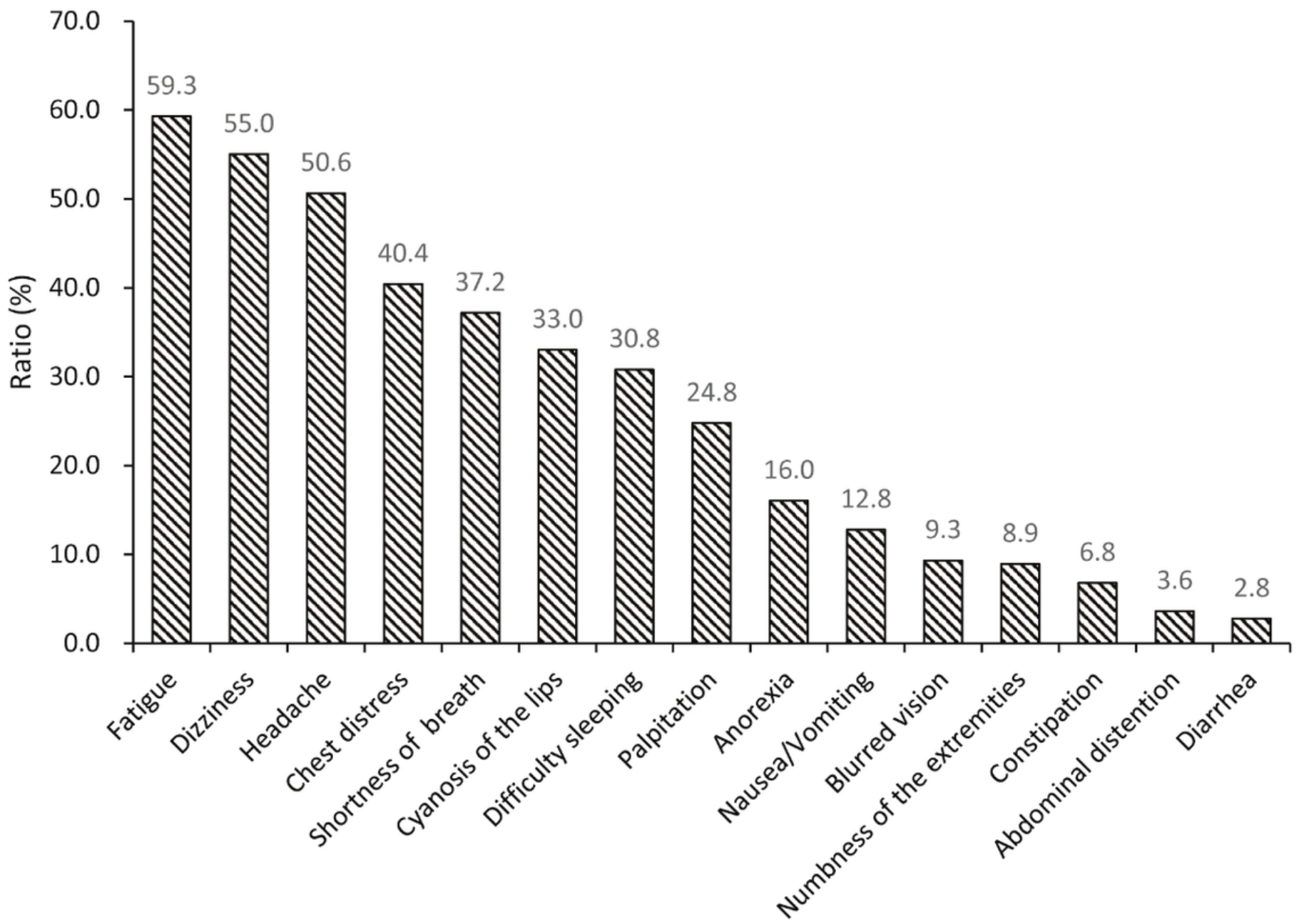


Difference in the positive rate of symptoms in the population.

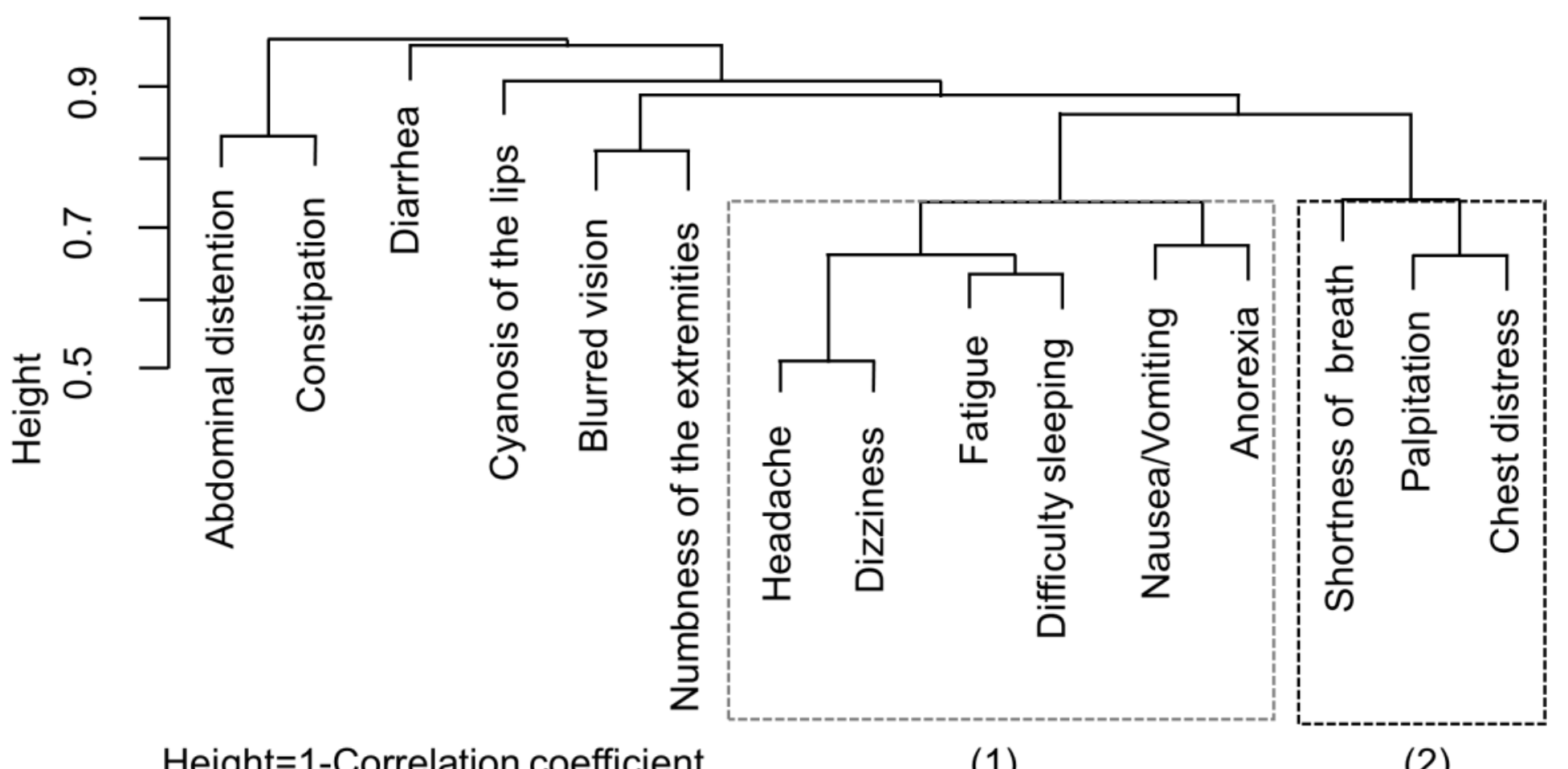

Height=1-Correlation coefficient

(1)

(2)

Figure 4

AMS symptom cluster dendrogram.

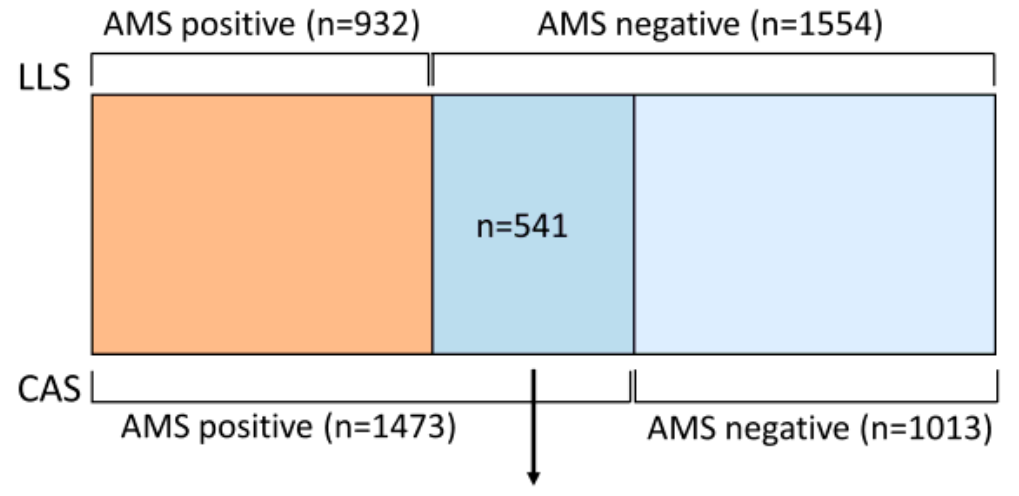

Mild AMS $=523(96.7 \%)$

Moderate AMS $=14(2.6 \%)$

Severe AMS $=4(0.7 \%)$

AMS positive according to both the LLS and CAS

AMS positive according to the CAS and AMS negative according to the LLS

AMS negative according to both the LLS and CAS

Figure 5

Main characteristics of 541 AMS-positive subjects according to the CAS and AMS-negative subjects according to the LLS 
Input variable importance

$\square 1.0 \square 0.8 \square 0.6 \square 0.4 \square$

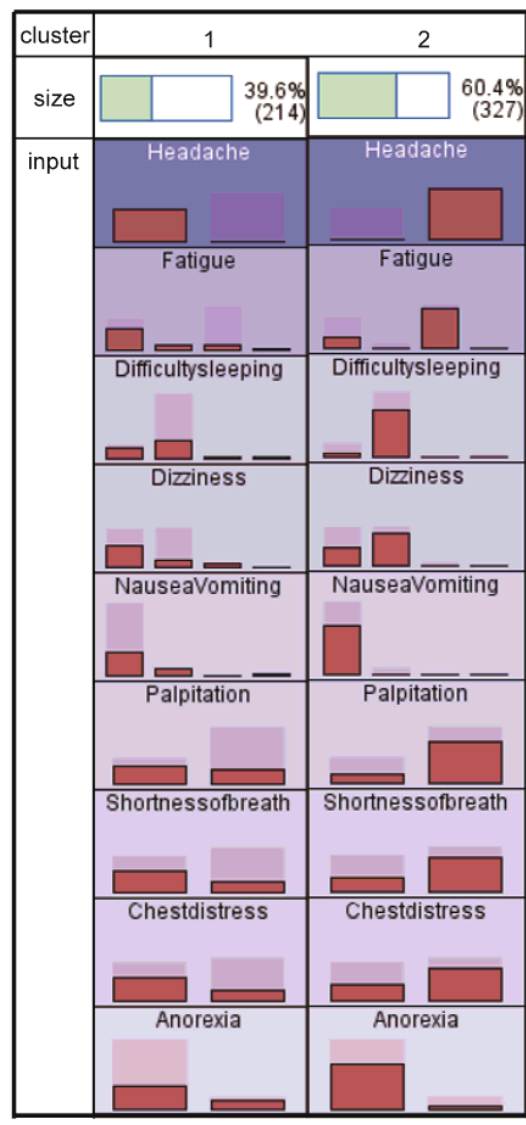

a. The distribution of clustering symptoms $\square 1 \square 2$
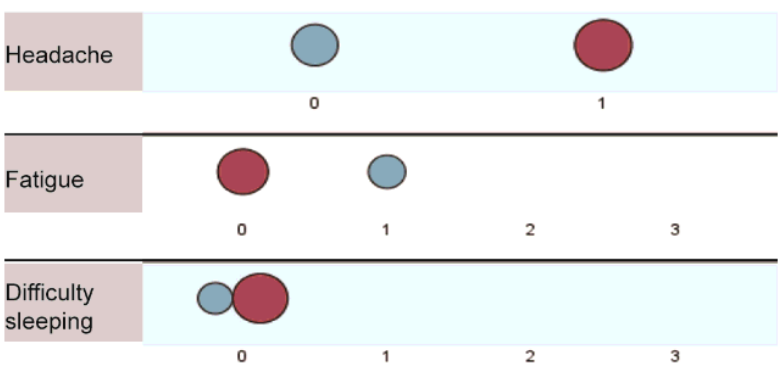

\begin{tabular}{lllll}
\hline Dizziness & & & \\
& 0 & 1 & 2 & \\
\hline $\begin{array}{l}\text { Nauseal } \\
\text { Vomiting }\end{array}$ & 1 & & & \\
\hline & 0 & 1 & 2 & 3 \\
\hline
\end{tabular}

Palpitation $0 \begin{aligned} & 1 \\ & 0\end{aligned}$

\begin{tabular}{lll}
\hline $\begin{array}{l}\text { Shortness } \\
\text { of breath }\end{array}$ & & 1 \\
\hline $\begin{array}{l}\text { Chest } \\
\text { distress }\end{array}$ & 0 & 1 \\
\hline Anorexia & 0 & 1
\end{tabular}

b. The comparison of clustering symptoms

\section{Figure 6}

The distribution and comparison of clustered symptoms using two-step clustering 